\title{
USING FINANCIAL MARKETS INFORMATION TO IDENTIFY OIL SUPPLY SHOCKS IN A RESTRICTED VAR*
}

\author{
MARKO MELOLINNA \\ Bank of Finland, \\ Monetary Policy and Research Department, \\ P.O. Box 160, FI-00101 Helsinki, Finland; \\ email: marko.melolinna@pp.inet.fi
}

\begin{abstract}
This paper introduces a methodology for identifying oil supply shocks in to a small open economy. Financial market information is used to construct an identification scheme that forces the response to an oil shock of the restricted VAR model to be the same as that implied by futures markets. Due to the identification scheme, the model is only partially identified, and confidence intervals for impulse responses are calculated by using a bootstrapping procedure. The methodology is applied in illustrative examples to Finland and Sweden in a simple 5-variable model that includes key domestic and international macroeconomic variables. While oil supply shocks have an effect on domestic inflation in these countries during the past decade or so, the effect on domestic GDP is ambiguous. (JEL: C01, E32, E44)
\end{abstract}

\section{Introduction}

Due to the sharp rise in the price of crude oil, recent years have seen an increase in the number of papers studying the effects of oil shocks ${ }^{1}$ on macroeconomic variables. The main tools typically used in gauging the effects are either theoretically based macroeconomic models, or VAR models of different specifications. In pioneering papers of the latter category, Hamilton (1983)

\footnotetext{
* I am grateful to Heikki Kauppi, Juha Kilponen, Patrizio Pagano, Antti Ripatti, Jouko Vilmunen and an anonymous referee for helpful comments. I would also like to thank Stephen G. Donald, Richard J. Smith and Harald Uhlig for providing the programming code for their work.

${ }^{1}$ As a matter of definition, oil shocks are seen as oil price shocks in most studies, although an important difference between them and actual oil supply shocks is developed below. Throughout this paper, a positive oil shock refers to a supply shock that raises the price of oil.
}

and Burbridge and Harrison (1984) find a strong relationship between oil shocks and real economic variables in major industrial countries.

Since these early efforts at measuring the effects of oil shocks on real economy, there have been differing opinions and explanations offered on the importance of the effects. For example, Hooker (1996) finds few signs of the effects since the early 1970 's. Some authors have suggested non-linear oil price specifications, like Jimenez-Rodriguez and Sanchez (2005). Most of the results tend to favour a negative non-linear relationship between oil shocks and real variables in major industrial countries.

In recent years, a few studies have questioned the identification of an oil shock. Traditionally, an oil shock in the literature is defined as an oil price shock. However, in reality an oil price shock is an interaction between oil supply and 
demand shocks, which cannot be easily disentangled. Kilian (2006 and 2009) finds only limited short-run effects of oil supply shocks on real variables in the US. Kilian (2009) uses a structural VAR model to disentangle demand and supply shocks, finding that, in general, demand shocks tend to have a larger effect on the real economy and inflation than supply shocks.

Anzuini, Pagano and Pisani (2007) introduce a new methodology for identifying oil supply shocks in a structural VAR. Based on a methodology originally introduced by Faust, Swanson and Wright (2004) for studying monetary policy shocks in the US, they determine supply shocks as events in daily futures markets data and are thus able to identify a structural VAR. According to their results, positive oil supply shocks have a stagflationary effect on the US economy and they have contributed significantly to US recessions during the past 30 years.

This paper builds on this same methodology, which has advantages compared to the methodologies traditionally used in the literature to study the effects of oil shocks. ${ }^{2}$ First, in the spirit of Kilian (2009), it allows for a way of disentangling supply effects from demand effects through financial market information. Second, unlike most previous studies, it does not rely on recursive Choleski decompositions to identify the shocks but instead, the shocks can be identified with financial market data on crude oil futures prices.

In this paper, I extend the methodology used by Anzuini et al. (2007) in the following ways. First, my definition of daily oil supply shock events is more stringent as it requires that the shocks have actually affected the oil price on the day in question. Second, instead of the large country case, I study the effects of oil supply shocks in a small open economy. This implies using a restricted VAR specification instead of the more conventional full VAR specification, because some of the domestic variables of a small economy cannot realistically be expected to affect the international price of crude oil. Third, unlike Anzuini et al. (2007), I also use a partial identification scheme introduced by

${ }^{2}$ My methodology also resembles that used by Cavallo and $W u$ (2006).
Faust et al. (2004). This scheme is required due to the rank deficiency of the identification matrix. Furthermore, due to the restricted VAR specification, the test statistic used for testing the rank of the identification matrix is different from the test used in Faust et al. (2004). In particular, I use a test introduced by Robin and Smith (2000), which allows for the covariance matrix of the identification matrix to be rank deficient. This test is suitable for my model since, unlike most other tests (see, for example, Cragg and Donald (1997)), it is designed for cases where the covariance matrix can be less than full rank, or even unknown rank.

In an illustrative example, I apply my methodology to a simple model including key domestic and international macroeconomic variables for both Finland and Sweden. The results show that the oil supply shocks have no statistically significant long-term effect on real variables in these economies. On impact, there is a statistically significant negative effect of positive oil shocks on real economic acticity in Finland, but not in Sweden. There is evidence of positive oil supply shocks causing higher inflation, especially in Sweden, whereas in Finland, the effect is more ambiguous. These results are slightly different from the stagflationary effect found by Anzuini et al. (2007) in the case of the US.

The paper is organised as follows. Section 2 introduces the methodology with which oil supply shocks are extracted from financial markets information and linked to the VAR model, Section 3 deals with the financial market data of oil supply shocks, Section 4 introduces the model setup, Section 5 presents some results and Section 6 concludes. Some technical details about estimation procedures as well as auxiliary results are relegated to the appendices.

\section{Financial markets information and oil supply shocks}

\subsection{Identification of oil supply shocks}

Oil supply shocks in the model are identified by using information from oil futures contracts and a restricted VAR model. As regards the restricted 
VAR, the reduced form residuals are first linked to the structural form disturbances in a standard way.

Consider the reduced form VAR:

$$
A(L) Y_{t}=u_{t}
$$

where $Y_{t}$ is a $K \times 1$ vector of endogenous variables, $\sum_{j=0}^{p} A_{j} L^{j}=A(L)$ (where $p$ is the number of lags in the model), $A_{0}=I$ and $u_{t} \sim N(0, \Sigma)$ (where $\Sigma$ is the covariance matrix of the error term). $A(L)$ is an invertible $K \times K$ matrix and includes zero elements so that the system is a restricted VAR.

Equation (1) can be written in form (see Lutkepohl (2005)):

$$
Y_{t}=B(L) u_{t}
$$

where $B(L)=A(L)^{-1}=\sum_{i=0}^{\infty} B_{i} L^{i}$. Lutkepohl (2005) further shows that $B(L)$ can be derived recursively from the reduced form $A$ matrices:

$$
\begin{gathered}
B_{0}=I_{K} \\
B_{i}=\sum_{j=1}^{i} B_{i-j} A_{j} \quad \text { for } i=1,2, \ldots
\end{gathered}
$$

By assuming that the reduced form errors $u_{t}$ are related to the structural errors $\epsilon_{t}$ as follows:

$$
u_{t}=S \epsilon_{t}
$$

where $S$ is a full rank $K \times K$ matrix. (2), can then be made structural by writing it in terms of the structural shocks:

$$
Y_{t}=B(L) S \epsilon_{t}
$$

Assume that the first column of $S$ corresponds to the oil supply shock and call it $\alpha$. The vector of impulse responses of all variables in the restricted VAR to the oil shock is then (see Faust et al. (2004)):

$$
B(L) \alpha=\sum_{j=0}^{\infty} B_{j} \alpha L^{j} .
$$

The $k$ th element of the $K \times 1$ vector of lag polynomials $B(L) \alpha$ traces out the response of the $k$ th variable to the oil supply shock. The $B$ s are known from the reduced form estimates through (3). Hence, identifying the impulse responses requires picking the $K$ elements of $\alpha$.

To identify the oil supply shocks through $\alpha$, I use information contained in the futures contracts in correspondence of events classified as oil supply shocks. There are two steps in the identification procedure: (a) deriving the response of the expected oil prices from the futures and (b) imposing the equality between the restricted VAR impulse response of the oil prices to the oil shock and the response measured through the futures. The next three sections briefly describe first (b), then an identification issue related to (b), and finally (a).

\subsection{Matching responses of oil prices}

Assume that, in the case of no uncertainty, the response of the oil price identified from the futures markets at time $t+h$ to an oil price shock at time $t$ is $r_{h}, h=0,1, \ldots, K-1$. Hence

$$
r_{h}=B_{h, o i l} \alpha
$$

where $B_{h, o i l}$ is the row of $B_{h}$ corresponding to the oil price (in this case, the first row). Stacking all these equations for $h=0, \ldots, K-1$ :

$$
r=R \alpha
$$

where the rows of $R$ are the relevant row vectors $B_{h, o i l}$ and the elements of $r$ are the corresponding elements of $r_{h}$. The $B_{h, o i l}$ are derived from the reduced form model according to (3). The response of oil prices to an oil supply shock, $r_{h}$, can be obtained by using information contained in the futures (specified below). ${ }^{3}$

\footnotetext{
${ }^{3}$ One alternative method of identifying oil supply shocks is presented by Kilian (2009). However, the recursive identification methodology used in the paper requires the assumption of a vertical short-term supply curve for oil, and the definition of supply shocks differs slightly in my methodology. Hence, I do not consider it as an alternative here.
} 
The above system has $K$ unknowns (the elements of $\alpha$ ) in $K$ equations. Its solution, under the condition that $R$ is of $\operatorname{rank} K$, is:

$$
\alpha=R^{-1} r .
$$

\subsection{Partial identification}

In the above discussion, $r$ and $R$ are treated as if they were known with certainty. In reality, uncertainty in both $r$ and $R$ must be taken into account for inference. Specifically, if $R$ is not full rank, then the system cannot be identified with certainty. When I test the rank of the $R$ matrix in the example cases, it turns out the full rank assumption of equation (9) fails (see discussion in section 5.2. for details). Thus the system is only partially identified (see Faust et. al (2004)). The reason for this is also intuitively clear: the response of the oil price variable is very similar at different horizons $\left(B_{h, \text { oil }} \approx B_{h+1, \text { oil }}\right)$, so after imposing the impulse response in the VAR to the shock at horizon $h$, one gets very little additional identifying power from also imposing the response at $h+1, h+2$ and so on.

Partial identification does not doom inference, but proper care must be taken when identifying the model. In particular, the most striking implication of partial identification is that point estimates of the impulse responses must be given up and only confidence intervals can be considered (see Faust et. al (2004)).

To see how these confidence intervals are constructed, consider a scalar parameter $f$, which could be, for example, the impulse response of a particular variable to an oil shock at a particular horizon. Calling all the reduced form parameters of the VAR $\theta, f$ is a function of $\theta$ and $\alpha ; f(\theta, \alpha)$.

The vector $\alpha$ as described above is the contemporaneous effect of an oil supply shock on each variable in the restricted VAR. Economic reasoning and other considerations should allow us to make some restrictions on the sign and magnitude of the elements of $\alpha$, and so to restrict the parameter space for $\alpha$ to be in some set $A^{+}$. These restrictions are detailed below.

The key step in forming a confidence interval for $f$ is to form a confidence interval for $\alpha$ from the restrictions that $\alpha$ must lie in $A^{+}$and that $R \alpha=r$, taking into account the uncertainty in $r$ and $R$, and without relying on assumptions about the rank of $R$. The construction of this confidence interval follows the work of Stock and Wright (2000) and is discussed in detail in Appendix A. I construct a confidence interval for $\alpha$ with about $70 \%$ coverage this way (i.e., slightly less than two standard deviations ${ }^{4}$ ), and call this set $A$.

Next consider forming a confidence interval for $f$ conditional on the point estimate of the reduced form parameters, $\hat{\theta}$. Under full identification, this would be associated with a unique estimate of $f$. Under partial identification, there is a range of $f(\hat{\theta}, \alpha)$, consistent with the $\alpha$ vectors that are included in $A$. Thus the confidence interval is

$$
\left[\inf _{\alpha \in A} f(\widehat{\theta}, \alpha), \sup _{\alpha \in A} f(\hat{\theta}, \alpha)\right] .
$$

This confidence interval needs to be extended to a situation where uncertainty in $\alpha$ and $\theta$ is taken into account. For any fixed $\alpha$, the model is identified, and a conventional bootstrap (described in Appendix A) can be used to construct a $85 \%$ confidence interval for $f(\hat{\theta}, \alpha)$. Let this confidence interval be $[\operatorname{cl}(\alpha), c u(\alpha)]$. Next, form the outer envelope of all of these intervals across all $\alpha$ s in $A$, as $\left[\inf _{\alpha \in A} c l(\alpha), \sup _{\alpha \in A} c u(\alpha)\right]$. This confidence interval has asymptotic coverage of at least $70 \%$, from the Bonferroni inequality, because asymptotically, (i) the confidence interval $A$ for $\alpha$ has asymptotic coverage of $85 \%$ and (ii) the bootstrap confidence interval has $85 \%$ coverage for any fixed $\alpha$. The technique is conservative in that coverage may be asymptotically higher than 70 percent. $^{5}$

\subsection{Measuring oil price shocks using futures}

This section develops the claim, taken as given above, that the impulse response of the oil price

\footnotetext{
4 The confidence interval is thus close to $68 \%$, which is standard in some VAR literature.

${ }_{5}^{5}$ For example, even when the true $\alpha$ is not in $A$, the confidence interval may contain the true $f$.
} 
to oil supply shocks can be measured directly from the crude oil futures market. ${ }^{6}$

An oil futures contract for date $t+h$ is a bet on the oil spot price s on date $t+h$ (where $h$ is the number of months forward from a particular day $t$ ). Parties to the $h$-period contract agree at time $t$ on a price $f_{t+h}$ for oil to be delivered at $t+h$. Standard no-arbitrage condition implies that:

$$
0=E_{t}\left[m_{t+h}\left(s_{t+h}-f_{t+h}\right)\right]
$$

where $m$ is the stochastic pricing kernel. This leads to:

$$
f_{t+h}=E_{t} s_{t+h}+\frac{\operatorname{cov}\left(s_{t+h}, m_{t+h}\right)}{E_{t}\left(m_{t+h}\right)}
$$

which states that the futures price is equal to the expected future spot price plus a risk term. The focus here will be on the change in oil futures prices $\Delta_{d_{t}} f_{t+h}$ on the day $d_{t}$ of events classified as oil supply shocks. Hence, as long as the risk term in equation (11) does not change on the day of the event, we can write:

$$
\text { (12) } \begin{aligned}
\Delta_{d_{t}} f_{t+h} & =f_{t+h}^{d_{t}}-f_{t+h}^{d_{t}-1} \\
& =E_{d_{t}} s_{t+h}-E_{d_{t-1}} s_{t+h} \equiv \Delta_{d_{t}}^{e} s_{t+h}
\end{aligned}
$$

where $\Delta_{d_{t}} s_{t+h}$ is the change in the expectations about the spot price at $t+h$ due to the unanticipated event that has hit the market at date $d_{t}$.

In the restricted VAR, the expected oil price at $t+h$, conditional on information in the dataset at $\mathrm{t}$ is:

$$
E_{t} s_{t+h}=\sum_{i=0}^{\infty} B_{h+i, o i l} S \epsilon_{t-i}
$$

The change in expectations on day $t$ for the price of oil at $t+h$ is due to changes in shocks on day $t, \Delta_{d_{t}}^{e} \epsilon_{t}$, given that all the past $\epsilon \mathrm{s}\left(\epsilon_{t-1}, \epsilon_{t-2}, \ldots\right)$ are known at the beginning of day $t$. In order to single out the changes in expectations due to the oil shock $\epsilon_{\text {oil, },}$, and assuming again that the risk premium does not change, (12) can be written:

6 This section draws on Faust et. al (2004), who use a similar strategy to identify shocks in the US federal funds rate market.
(14) $\Delta_{d_{t}} f_{t+h}=B_{h, o i l} \alpha \Delta_{d_{t}}^{e} \epsilon_{o i l, t}+B_{h, o i l} S^{*} \Delta_{d_{t}}^{e} \epsilon_{t}$

where matrix $S^{*}$ is equal to $S$ with the first column replaced by zeros and $\alpha$ is the first column of $S$. The second term can be assumed to be zero: news does not lead markets to reassess views of the other shocks as the shocks are independent. Then:

$$
\Delta_{d_{t}} f_{t+h}=B_{h, o i l} \alpha \Delta_{d_{t}}^{e} \epsilon_{o i l, t}
$$

Combining equations (7) and (15):

$$
\Delta_{d_{t}} f_{t+h}=r_{h} \Delta_{d_{t}}^{e} \epsilon_{o i l, t}
$$

where $r_{h}=B_{h, \text { oil }} \alpha$ is the impulse response of the oil price to the oil shock at horizon $h$. Since this equation holds for every $h$, including 0 , when $\Delta_{d_{t}} f_{t} / r_{0}=\Delta_{d_{t}} s_{t} / r_{0}$, the unobserved error term $\epsilon$ can be substituted out, because then $\Delta_{d_{t}} s_{t} / r_{0}=\Delta_{d_{t}}^{e} \epsilon_{o i l, t}$. This yields:

$$
\Delta_{d_{t}} f_{t+h}=\frac{r_{h}}{r_{0}} \Delta_{d_{t}} s_{t} .
$$

This equation measures the proportionality of change in the futures price compared to the spot price on day $t$ when the shock occurs. The factor of proportionality is the same for each shock, while, of course, the magnitude of different shocks can be different. This factor of proportionality is estimated from the futures contract data for each $h$ and then used in (7) to obtain the estimated $\hat{r}_{h}$ for the identification strategy.

The above steps allow for recovering the point estimate of $\alpha$ in equation (9) and, thus, the identification of the model.

\section{Extracting the shocks from financial markets data}

The key to the identification strategy described above is identifying individual oil supply shocks - or events - in the financial markets. The procedure is similar to that introduced by Faust et al. (2004) for monetary policy shocks and Anzuini et al. (2007) for oil shocks. The procedure is carried out based on information gathered from The Monthly Energy Chronology, compiled by the United States Energy Information 
Table 1. Types of identified oil supply shocks

\begin{tabular}{lc} 
Type of shock & Percentage of all shocks \\
\hline OPEC Meetings and statements by OPEC officials & 44 \\
Political and UN statements related to Iran nuclear programme and Iraq food-for-oil programme & 18 \\
Involuntary supply changes due to accidents and terrorist activity & 9 \\
Military operations and unrest in the Middle East region & 8 \\
Voluntary short-term supply changes by non-OPEC nations & 6 \\
Industrial action & 4 \\
Adverse weather conditions & 4 \\
Yukos-affair in Russia & 4 \\
US SPR changes & 3 \\
Major new oil discoveries & 1 \\
\hline
\end{tabular}

Administration. ${ }^{7}$ Based on this source, I select major events, which can be construed as oil supply shocks, and which have moved the price of oil on the day ${ }^{8}$ of the event (or on the next day, if the event occured while the US markets were closed). Futhermore, I also cross-check the shocks with Bloomberg news service, which produces a daily report on major factors driving the oil price during a particular day, to ascertain that the selected shocks have had a significant effect on oil price movements on the day they took place. This cross-checking is a unique feature of my methodology and should help ensure the shocks were actually significant factors in market movements of the day, although obviously other factors may also have influenced oil prices (see also footnote 11).

The identification of the shocks requires that daily surprise price changes in the crude oil spot price and the crude oil futures price at different horizons are collected from the days when the oil supply shocks took place. ${ }^{9}$ This allows for an OLS regression that produces the factors of proportionality for equation (17).

The definition of an oil supply shock builds on Anzuini et al. (2007). These shocks include new

7 This chronology lists major daily events that have affected the price of crude oil and is available on the website www.eia.doe.gov.

8 Note that the shocks are assumed to affect the price of the oil immediately when market participants gain knowledge about them, i.e. there are no information and/or trading barriers in the markets. Since oil futures markets are very liquid and transparent, this is intuitive, and also conforms with Faust et al. (2004).

9 The price data used is that of the West Texas Intermediate (WTI) crude oil, which is the North American benchmark crude oil type. information that becomes available to the market, and this information has direct consequences for the future amount of crude oil produced. These kind of news include, for example, OPEC production decisions, outbreaks of war and terrorist attacks. There are also shocks that have more direct effects on the amount of crude oil made available in the global oil markets, rather than the actual production of oil. These include, for example, announcements regarding the United States strategic petroleum reserves (SPR) and adverse weather conditions which may hinder the transfer of crude oil to oil refineries. Nevertheless, the price responses of these shocks can be expected to be similar to actual production shocks, so they are also included in the analysis.

Overall, 140 shocks ${ }^{10}$ that could be expected to have an effect on oil supply were identified between 1996 and 2006. The time period considered was determined by data availability issues related to the Energy Chronology as well as the fact that the model sample in the example cases (described below) is close to this time period. The percentage distribution of different kinds of shocks is set out in Table 1. Of course, the list is not unambiguous and different news events may be listed by other sources. Nevertheless, I maintain it is a good representative sample of oil supply shocks to have taken place during the time period considered.

By far the biggest group of shocks is OPEC production decisions and other OPEC statements. This is not surprising; these decisions take place at regular intervals and can in some sense be compared with central bank policy de-

10 List of the shocks is available from the author on request. 


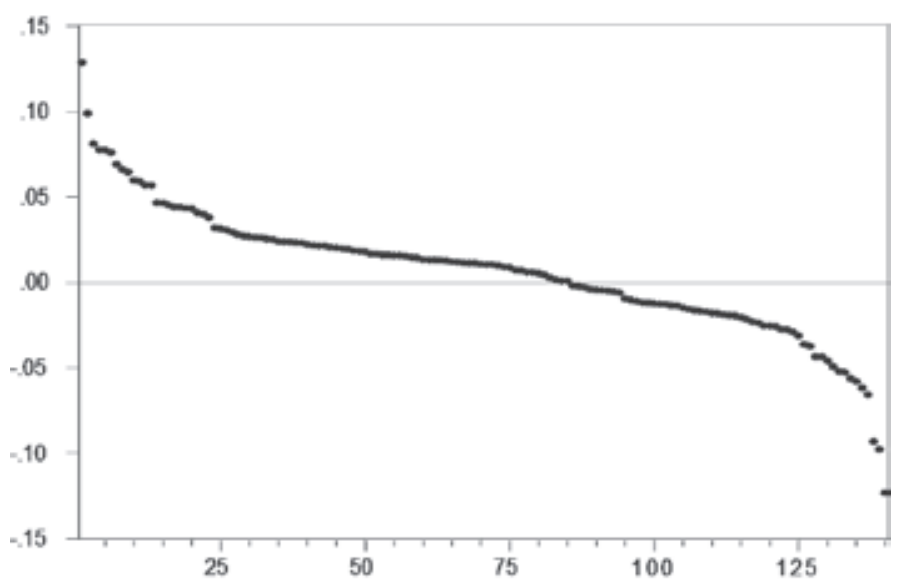

Figure 1. Ordered daily surprise changes in logged spot price

cisions in monetary policy models (even though non-compliance of OPEC members blurs this analogy somewhat). Other oil supply shocks that feature regularly are related to political and military conflicts in the Middle East region.

Even though my list of oil supply shocks differs slightly from that of Anzuini et al. (2007) (mainly due to the cross-checking and the different time horizon used), conclusions about the shocks are largely very similar. The shocks have had a large effect on the spot price of oil; on average, the

surprise change in the spot oil price has been about $3 \%$, and the largest changes have been over $10 \%$ in absolute value (Figure 1 ).

The scatter plot of logged oil spot price changes due to the shocks vis-a-vis oil futures price changes at different horizons shows that the linearity assumption implicit in Equation (14) is satisfied; the futures prices change in linear proportion to the size of the spot price change (Figure 2).

To derive $r$ (see equation 8), the event-day changes in futures contracts prices for horizons 1-4 months are regressed on the oil spot price change on that day. The impulse responses are taken as the OLS point estimates of these regressions. They are listed in Table 2, along with their standard errors in parentheses. According to the results, the effect of the shocks gradually diminishes to about $70 \%$ of the impact effect. The standard errors suggest that all effects are strongly significant within the 4-month period.

Table 2 also lists different specifications of the events. In particular, one may assume that the OPEC decisions are not entirely exogenous, and the fact that markets have preordained expectations on their outcome could contaminate the price data on the actual event-day. However, the fourth column that excludes the OPEC decisions shows that the results are very similar to those obtained with the full event set. The same can be said for an event set that only includes price increases. Furthermore, the selection procedure used in my analysis may introduce upward bias in the coefficients. As a robustness check for this effect, I use a subset of the largest shocks in the analysis, and, again, the results are virtually unchanged. Anzuini et al. (2007) also lists other specifications ${ }^{11}$ of the event set, but the conclusion stays the same. Thus, the results are very robust to different event sets, and there seems to be no reason to abandon using the full original event set in the analysis.

This approach to the identification of the system requires that futures markets provide an efficient forecast of the change in the time path of

${ }^{11}$ Anzuini et al. (2007) also consider the question of the oil price data being contaminated by releases of important macroeconomic data on the event day and find that the results stay similar to the full event set. For the purposes of my analysis, I take these results as given. 

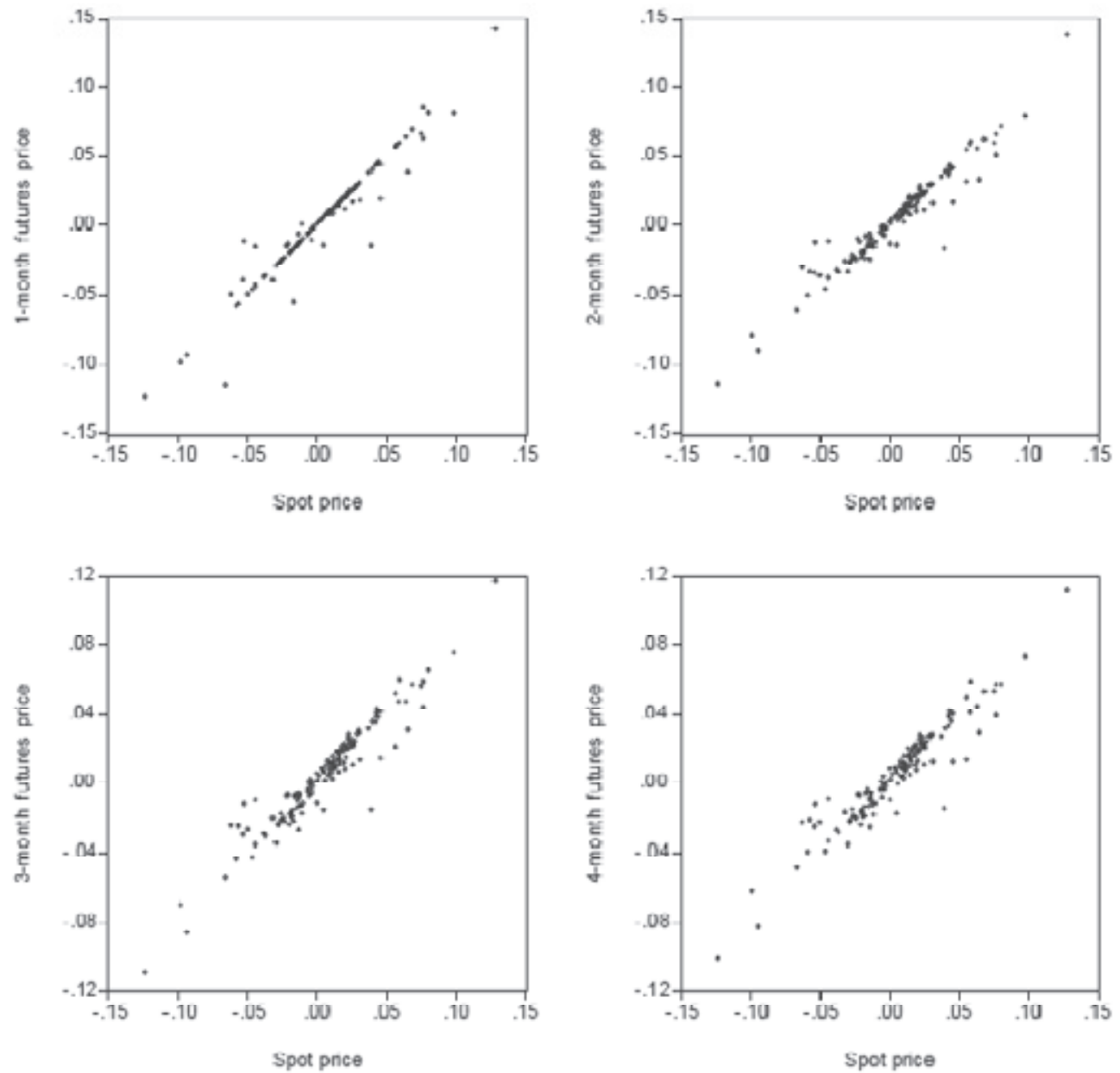

Figure 2. Oil spot price surprise changes and futures price changes (in logarithms)

the oil price, or at least, that risk premia in oil futures do not change. Following Anzuini et al. (2007), I test the assumption that at horizons 1-4 month-ahead oil futures provide efficient forecasts for subsequent oil spot price changes by regressing the log of average oil price (the variable included in the restricted VAR) on the log of the forecast for month $t$ implied by oil futures at month $t-1, \ldots, t-4$. The test (with $95 \%$ confidence interval) that the slope coefficient is equal to 1 is supported in every case (Table 3 ) and all estimates of the intercepts are not different from zero, but in some cases a joint test fails to reject the assumption of the intercepts being equal to zero and the slopes being equal to 1 .
This result is similar to that in Anzuini et al. (2007). Yet, as long as the non-zero intercept is related to a constant risk premium, the identification scheme is valid. It would only be undermined by a varying risk premium, and this possibility is limited due to the short time period of the shock (one day). ${ }^{12}$ Therefore, a constant risk

12 Standard coefficient stability tests suggest that the risk premium is not constant over the entire efficiency test sample horizon for futures of longer maturities. For example, the p-value of the F-statistics of the Quandt-Andrews Breakpoint Test is below 0.01 for all maturities. However, there are no clear structural breaks and the recursive estimates of the constant term change slowly. This suggests that risk premia do not change on a daily basis. 
Table 2. Impulse responses of oil price to oil supply shocks

\begin{tabular}{lccc}
\hline$h$ & $1996-2006$ & Positive shocks & Non-OPEC shocks \\
\hline 1 & $0.95(0.02)$ & $0.93(0.02)$ & $0.95(0.03)$ \\
2 & $0.84(0.02)$ & $0.85(0.03)$ & $0.83(0.03)$ \\
3 & $0.76(0.02)$ & $0.77(0.03)$ & $0.74(0.03)$ \\
4 & $0.71(0.02)$ & $0.72(0.03)$ & $0.69(0.02)$ \\
\hline Obs & 140 & 85 & 93 \\
\hline
\end{tabular}

OLS estimates, standard errors in parentheses. The regression is the percentage change in the futures price contract at $t+h$ on the surprise change in the spot price.

Table 3. Forecast efficiency tests for oil price futures.

\begin{tabular}{cccccc}
\hline$h$ & Constant $(\alpha)$ & Slope $(\beta)$ & $\begin{array}{c}\mathrm{p} \text {-value } \\
(\beta=1)\end{array}$ & $\begin{array}{c}\mathrm{p} \text {-value } \\
(\alpha=0)\end{array}$ & $\begin{array}{c}\mathrm{p} \text {-value } \\
(\beta=1 \text { and } \alpha=0)\end{array}$ \\
\hline 1 & $0.05(0.05)$ & $0.99(0.02)$ & 0.42 & 0.35 & 0.40 \\
2 & $0.11(0.07)$ & $0.97(0.02)$ & 0.18 & 0.11 & 0.06 \\
3 & $0.15(0.08)$ & $0.96(0.03)$ & 0.13 & 0.07 & 0.01 \\
4 & $0.17(0.09)$ & $0.96(0.03)$ & 0.16 & 0.07 & 0.01 \\
\hline
\end{tabular}

OLS estimates, standard errors in parentheses. The regression is the log spot price at date on the log futures price contract at date $\mathrm{t}$ expiring $\mathrm{h}$ months later.

premium is assumed and thus the identification scheme is deemed to be valid for the analysis.

\section{Restricted VAR setup for a small open economy}

The methodology described above closely follows that used by Anzuini et al. (2007) for the US economy. The difference is that as I am modelling a small open economy, where some of the domestic variables cannot realistically be expected to affect the international price of crude oil, a full-VAR specification is no longer efficient. Furthermore, the proposed specification of variables used in the VAR differs from that of Anzuini et al. (2007) as well as earlier studies.

The basic idea is to divide the variables in the model into two categories: international and domestic. Variables defined as international can affect all the other variables directly in the model, whereas domestic variables are not allowed to affect international variables directly. A simple 5-variable setup is illustrated in Figure 3. The 5 variables in the model are the price of oil (oil), a measure of global economic activity ("world GDP"), short-term interest rate differential between the domestic currency and the currency in which the oil price is quoted (US dollar) (r-r*), a measure of domestic economic activity (GDP) and domestic inflation (Inflation). ${ }^{13}$

The channels of direct effects are marked with directional arrows in Figure 3. The price of oil as well as global economic activity is allowed to affect all the other variables directly. This is intuitive, since these two variables can be expected to affect domestic variables of small countries through, for example, trade channels. On the other hand, domestic variables of a small economy cannot be expected to have a significant effect on global GDP or the price of oil, since by definition their weight in the global economy is small. ${ }^{14}$

13 Typically, VAR models in the literature studying oil shocks include variables at least measuring inflation, domestic economic activity and interest rates. My open-economy model attempts to capture links between international variables as well, which justifies the inclusion of measures of global economic acticity and the interest rate differential. The latter is crucial for the identification strategy, but is also justified based on consideration of standard open economy macroeconomic models. Of course, alternative specifications may also be considered. However, the focus here is on checking the validity of the methodology introduced above and not so much on finding the perfect empirical model.

14 In the case of Finland and Sweden (see applications below), the weight is less than $0.5 \%$ of global GDP in both cases. 


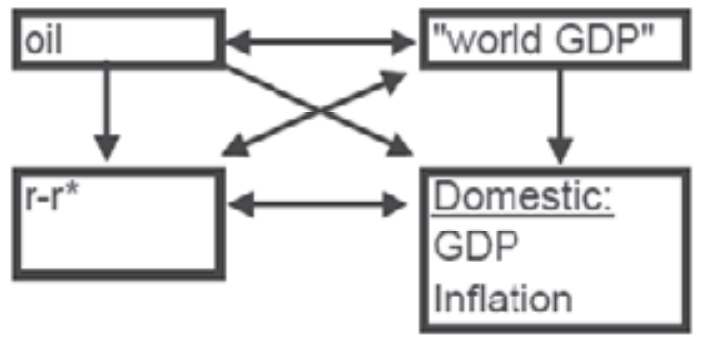

Figure 3. A 5-variable restricted VAR setup

The key variable linking the international and domestic variables in the model is the interest rate differential, which is included in order to capture the cyclical links between the domestic economy and the largest economy in the world. It has direct links to both international and domestic variables since it includes an important international variable (interest rate of the largest economy in the world) and a domestic variable (domestic interest rate). In the benchmark case, interest rate differential is not allowed to have an effect on oil price. This is slightly contentious, but it is supported, for example, by Frankel (2006), who finds that interest rates do not have a statistically significant effect on oil prices in the US between 1950 and 2005. The decision taken in my model specification is also congruent with the literature dealing with monetary policy shocks in VAR models, which typically assume that other variables react to shocks with a lag. My specification also fits well with previous literature (see Barsky and Kilian (2004), and Anzuini, Lombardi and Pagano (2010)), which finds that monetary policy shocks transit through to oil prices mainly indirectly via growth and inflation. ${ }^{15}$

As a consequence of these restrictions on the contemporaneous channels, estimating the model with OLS as a full VAR model is no longer asymptotically efficient. Instead, estimation is

15 Note that the near-VAR specification used in my analysis does not preclude interest rate shocks having an effect on the oil price with a lag indirectly through the other variables (especially world GDP), as the shock is propagated through the system through the $B$ and $S$ matrices in equation (5). How this would happen is not the subject of the current study, however, as the monetary policy shock is not identified. carried out as restricted VAR, using Feasible Generalised Least Squares (FGLS). The resulting $A$ matrix in equation (1) for each lag $p(p>1)$ is

$\left[\begin{array}{ccccc}a_{p, 11} & a_{p, 12} & 0 & 0 & 0 \\ a_{p, 21} & a_{p, 22} & a_{p, 23} & 0 & 0 \\ a_{p, 31} & a_{p, 32} & a_{p, 33} & a_{p, 34} & a_{p, 35} \\ a_{p, 41} & a_{p, 42} & a_{p, 43} & a_{p, 44} & a_{p, 45} \\ a_{p, 51} & a_{p, 52} & a_{p, 53} & a_{p, 54} & a_{p, 55}\end{array}\right]\left[\begin{array}{c}\text { oil }_{t-p} \\ w g d p_{t-p} \\ r d_{t-p} \\ \text { hicp }_{t-p} \\ g d p m_{t-p}\end{array}\right]$

and as a consequence equation (8) (using the recursions of equation (3)) is of the following form:

$$
\left[\begin{array}{l}
r_{0} \\
r_{1} \\
r_{2} \\
r_{3} \\
r_{4}
\end{array}\right]=\left[\begin{array}{ccccc}
b_{0,11} & 0 & 0 & 0 & 0 \\
b_{1,11} & b_{1,12} & 0 & 0 & 0 \\
b_{2,11} & b_{2,12} & b_{2,13} & 0 & 0 \\
b_{3,11} & b_{3,12} & b_{3,13} & b_{3,14} & b_{3,15} \\
b_{4,11} & b_{4,12} & b_{4,13} & b_{4,14} & b_{4,15}
\end{array}\right]\left[\begin{array}{c}
s_{11, \text { oil }} \\
s_{21, \text { wgdp }} \\
s_{31, \text { rd }} \\
s_{41, \text { hicp }} \\
s_{51, \text { gdpm }}
\end{array}\right]
$$

where the 5 variables are ordered, from the first row to the last, as oil price (oil), global economic activity $(w g d p)$, interest rate differential $(r d)$, domestic inflation (hicp) and domestic economic activity $(\mathrm{gdpm})$, the $\mathrm{r}$ vector is on the left hand-side, the $\mathrm{R}$ matrix is the matrix with the $b$-coefficients (which can be rank deficient, see Appendix B) on the right-hand side, and the $\alpha$ vector is the on the far right. The different rows of R reveal the "coefficient" effects of the original oil shock through the $B$ matrices (see Equation (7)) back to the oil price at different horizons (measured here in months). At period zero, when the oil supply shock takes place, the only effect naturally occurs through the coefficient on the oil price variable itself $\left(b_{0,11}\right)$. At period 1 , there is also an effect from the $w g d p$ variable $\left(b_{1,12}\right)$, and in period 2 , from the $r d$ variable $\left(b_{2,13}\right)$. The domestic variables' effect occurs at periods 3 and 4 . 


\section{Applications: Finland and Sweden}

The methodology described in the previous section is applied in illustrative examples to Finland and Sweden, both of which can be described as small open economies; the value of GDP of both countries is less than $1 \%$ of global GDP, and foreign trade, calculated as the sum of the value of imports and exports of goods and services, was over $80 \%$ of GDP in Finland and over 90 $\%$ of GDP in Sweden in 2006.

\subsection{Data and estimation}

The dataset in both cases includes short-term (3 month) interest rate differential between the home country and the United States, the price of crude oil in US dollars (WTI quality) and a composite measure of industrial production in the OECD countries, published by the OECD. This industrial production measure represents global economic activity. Obviously such a measure has various shortcomings; it only measures a fraction of GDP as services are not included, and it does not cover non-OECD countries. However, no other readily available measure of monthly global economic activity exists, so I include this one with the obvious caveats. ${ }^{16}$

The oil price could be measured in euros (and Swedish kronas in the Swedish case) instead of dollars, but in reality this would lead to substantial data timing problems, because the oil market shocks are listed in US time. In any case, tentative estimations (made by converting the oil price into local currency) indicate that the results would not be dramatically different if local currency oil prices were used. Furthermore, part of the timing problem could in theory be avoided by measuring the shocks in dollar-denominated oil spot and futures prices and then convert-

\footnotetext{
16 Kilian (2009) introduces a monthly measure of real economic activity based on shipping freight rates. However, such a measure can be expected to be contaminated by demand and supply in the international shipping markets. Furthemore, as my intention (unlike that of Kilian (2009)) is to find a proxy for the world GDP, and as the correlation of $O E C D$ industrial production with the world GDP is much higher than that of Kilian's measure, I do not consider this indicator to be suitable for my model.
}

ing these to local currencies through foreign exchange forward quotations, but in practice forex forward data limitations render this idea impossible. Thus oil price data quoted in US dollars is used in the estimation of the models.

As far as domestic variables are concerned, for both countries inflation is measured by the Harmonised Index of Consumer Prices, and GDP is measured by a monthly GDP indicator. The latter is especially useful, since it covers, at least in principle, services as well as industrial activity, and is thus superior to production indicators, like, for example, monthly industrial production traditionally used in this type of literature.

Due to data availability issues both samples are relatively short; for Finland, the sample covers the years 1994-2006 and for Sweden, 1993-2006. With monthly data, this means that the sample size is over 150 for both cases. Although shorter samples are considered for robustness checks, the size of the sample does not allow for reliably examining short sub-samples, which would have been interesting especially in the case of Finland, since the monetary policy regime of the country changed with the inception of the European Monetary Union at the start of 1999. On the other hand, the sample period is well suited to investigating the effects of recent oil supply shocks, which presumably might differ from those experienced in the 1970's and 1980's.

All variables are in logs, except the interest rate differential, which is in percentage points. As is the convention in much of the literature in the field, raw data in levels without seasonal or other adjustments is used. Seasonal effects are captured by dummy variables. Error correction models are not considered, since the objective is not to recover long-term equilibrium relationships between the variables (and the short data sample would make this difficult anyway). Furthermore, the variables can be shown to be cointegrated, and Sims, Stock and Watson (1990) shows that using error correction models is unnecessary if there is enough cointegration amongst the variables. As mentioned above, the method of estimation is feasible generalised least squares.

The diagnostics of the models as regards residual normality and homoscedasticity do not point to any problems. However, the models in 
both cases are affected by a strong autocorrelation of the residuals, which is also confirmed by the Portmanteau and LM tests for autocorrelation. This autocorrelation cannot be corrected by including lags of 12 months or more, which is a usual remedy for the problem. However, shortening the sample from the beginning by 4 years helps to eradicate autocorrelation, although only borderline so in the case of Finland. ${ }^{17}$ Based on Akaike Information Criterion and the need to preserve as parsimonious a model as possible, the lag length of 4 was chosen for both models. ${ }^{18}$

\subsection{Results}

\subsubsection{Results with partial identification}

As indicated in the methodology description above, the rank of the $R$ matrix needs to be tested to ascertain whether full identification is possible. For both cases, it is clear that $R$ is reduced rank (for details see Appendix B). Thus, point estimates of impulse responses are not reliable and inference needs to be based on confidence intervals constructed by the partial identification procedure described in Appendix A.

Impulse responses constructed from the S-sets for Finland and Sweden are presented in figures 4 and 5, respectively. These responses have been restricted on the sign and size of their impact (i.e., the impulse responses at period zero) so that the sign conforms to economic theory (as is typical in the literature) and is the same as that of the FGLS point estimates, and the impact response confidence band includes the impact response vector (i.e. $\alpha$ ). ${ }^{19}$ This keeps the confidence intervals of the impulse responses bound-

17 This suggests that the data in the mid 1990's might be contaminated by the exceptional recessionary developments experienced in both countries in the early 1990's. This is obviously difficult to take into account in the models. Howe$v e r$, it does suggest that the strong autocorrelation of the benchmark models is not due to model misspecification. The results are also qualitatively robust to shorter samples.

18 This is a short lag length for monthly data. However, the results are also qualitatively robust to longer lag lengths.

19 In practice, the impact responses of all variables are restricted between zero and (in absolute value) the largest integer that allows the point estimate to be included in the range. This is a fairly weak assumption and conforms to that made, for example, in Anzuini et al. (2007). ed whilst keeping the restrictions much less strict than those traditionally applied in a recursive decomposition. As suggested by Faust et al. (2004), this makes the methodology more plausible than traditional recursive methods.

Confidence intervals are wide as expected, especially in the case of Finland. However, they do allow for some inference. The results are largely similar for these two countries. Both simulations indicate that the reaction of global real activity to an oil supply shock is initially slightly negative, but not permanently or significantly so. The reaction of the interest rate differential is slightly positive in Finland, implying that monetary policy has been quicker to react to oil price changes caused by oil supply shocks in Finland than in the US. For Sweden, no statistically significant conclusions about the interest rate variable can be made.

As regards the domestic variables, the reaction of headline inflation is stronger for Sweden. In fact, for Finland, the reaction isn't statistically significant for the benchmark specification. This is most probably due to certain country-specific factors (changes in indirect taxes and increased competition in services) that have had a strong effect on inflation in Finland in recent years. ${ }^{20}$ This may have rendered the Finnish headline inflation data difficult to interpret for oil supply shock purposes.

The reaction of the domestic GDP indicator is negative on impact for Finland, but quickly returns to zero. In fact, the impact response is puzzlingly large (between 2-4\% in absolute value to a $1 \%$ oil shock) in this specification. For Sweden, the profile of the impulse response also hints at a more negative response on impact than at longer horizons, although the response is never statistically significantly different from zero. These results are in contrast with, for example, Anzuini et al. (2007), who find that oil supply shocks have a stagflationary effect on the US economy during the past 40 years. However, there are various reasons why the effects of oil supply shocks might have been weaker during the past decade or so, which would help to explain my results. This issue is explored further below.

\footnotetext{
${ }^{20}$ For a shorter sample (1998-2006) and some longer lag lengths the reaction is significant for Finland as well.
} 
Finnish Economic Papers 1/2011 - Marko Melolinna
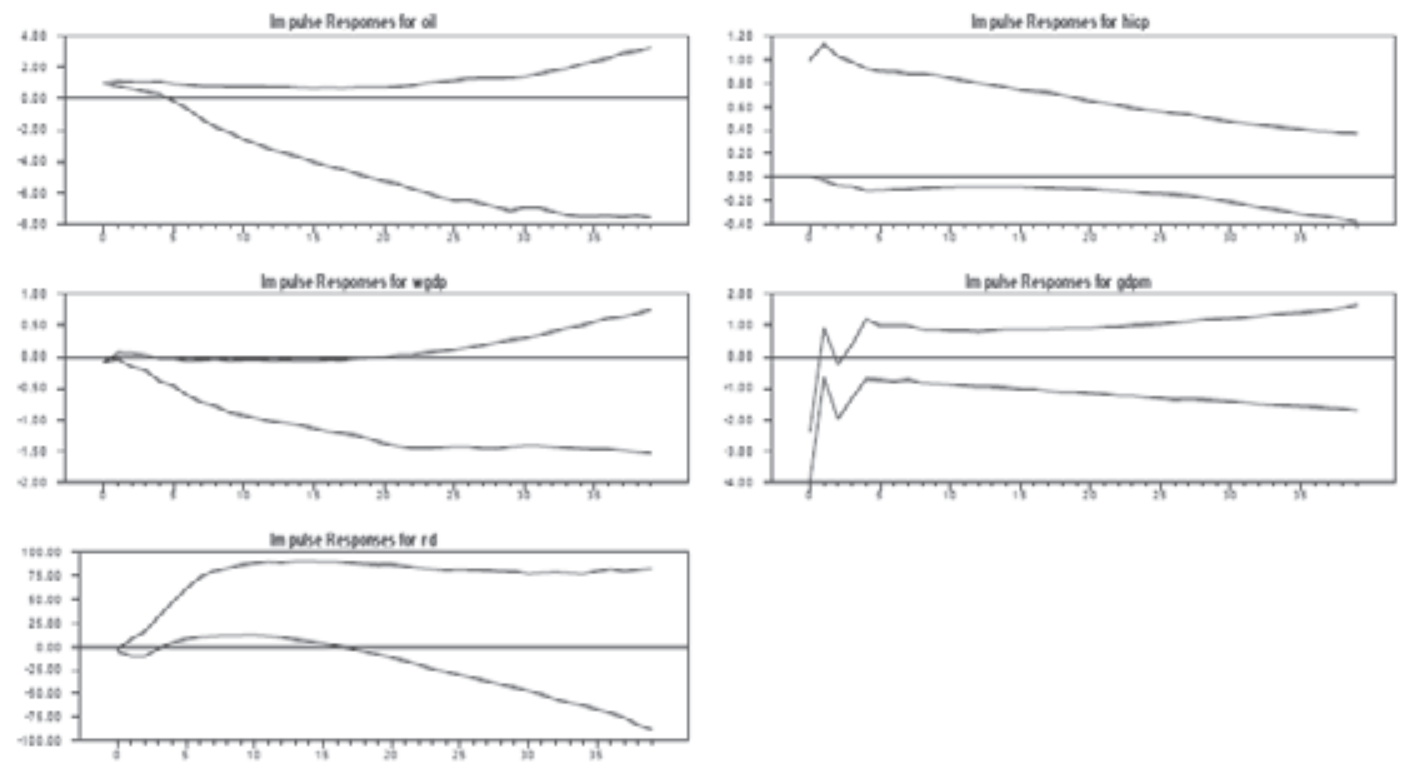

Figure 4. Impulse responses for Finland using partial identification and $70 \%$ confidence intervals
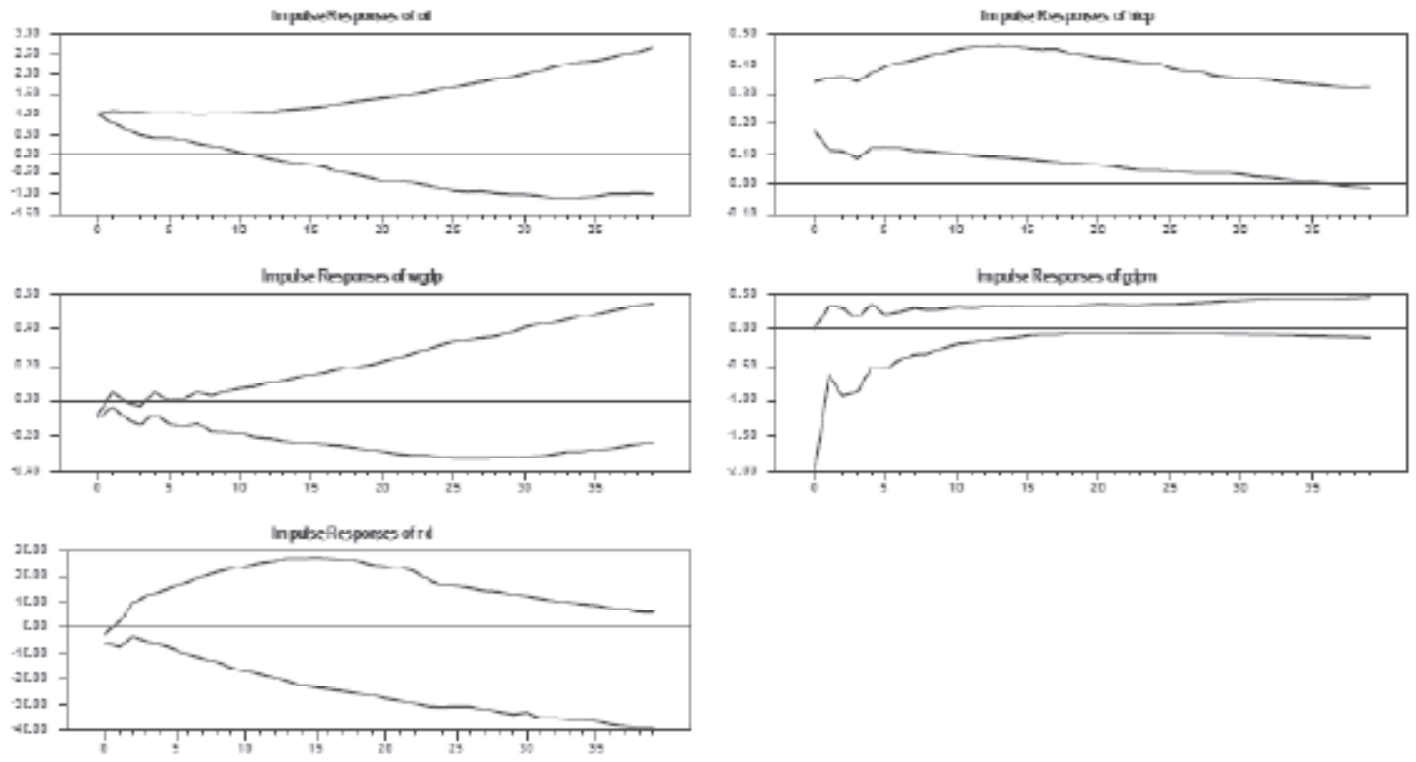

Figure 5. Impulse responses for Sweden using partial identification and $70 \%$ confidence intervals 


\subsubsection{Complementary results with a Monte Carlo experiment}

To complement the partial identification analysis, traditional point estimates were also computed. This was carried out through Monte Carlo integration (for technical details see Appendix $\mathrm{C}$ ), and uncertainty in both the $R$ matrix and its rank as well as the $r$ vector was taken into account. Impact responses obtained from 10,000 accepted draws for Finland and Sweden are presented in Appendix D, figures 7, 8, 9 and 10, with $68 \%$ confidence intervals. The first two graphs present the benchmark case, where the signs of the impact responses were restricted as described above for partial identification. ${ }^{21}$ For comparison, the next two graphs present a second case where the signs of the impact responses were not restricted, but the absolute size was restricted to be the same as in the benchmark case.

The results of the benchmark case for Monte Carlo integration are qualitatively close to those obtained with partial identification, although understandably the confidence intervals are much narrower. In the second case, the results are much more ambiguous, which illustrates the importance of the restrictions chosen. Certain restrictions, however, are intuitive. In particular, the domestic inflation variable includes the price of petrol (very closely correlated with the price of crude oil) by construction and can thus be expected to have a positive response on impact to a positive oil shock.

\subsubsection{Response of domestic GDP}

Perhaps the most interesting question pertains to the robustness of the domestic GDP impulse responses under different sign restrictions. In theory, a positive oil price shock can be expected to have a negative effect on the real economy of an oil-importing country. This is due to various channels. Firstly, there are a number of de-

\footnotetext{
${ }^{21}$ The restrictions on the impact response of the domestic GDP are slightly different in the Monte Carlo experiment, as the lower limit is restricted to be -1 (i.e., a $1 \%$ oil shock causes at most a $1 \%$ GDP response).
}

mand-side channels which will tend to dampen private consumption and investment. These include an income effect, which is caused by consumers having less money to spend on other items due to higher energy costs. On the supplyside, an oil price shock will increase firms' marginal costs, which is caused by the fact that oil is a factor of production. The price rise will thus have a negative effect on firms' output and employment. Furthermore, there is a deterioration in the terms of trade and income redistribution to the oil-exporting economies, and this will tend to suppress demand in the oil-importing economy. Oil price shocks can also have longlasting indirect effects, if they cause a need for a structural change towards less energy-intensive sectors and factors of production. There are also "confidence" effects, which can affect investment and consumption decisions, as well as wealth effects due to stock market responses, but these effects are obviously very difficult to measure or predict.

To gauge the effects of different specifications of the restrictions on the impact responses, using Monte Carlo integration, the impulse responses for the domestic GDP were calculated by allowing the impact response of this variable to vary. In particular, while the impact responses of the other variables were forced to have the same sign as their FGLS point estimates, the impact response of the domestic GDP was allowed to move from the space $\{-1,0\}$ to $\{-1,1\}$ at 0.2-unit steps. This kind of robustness check is, of course, arbitrary in its definitions, but the idea here is merely to catch a representative range of GDP impulse responses under different restrictions. This shows how sensitive the results can be to these restrictions, which is in line with the findings of Uhlig (2005) for monetary policy shocks. The results are presented in Figure 6 and - together with those detailed in the previous section - they clearly indicate how ambiguous the effect on the domestic GDP is for both cases.

These results on the ambiguity of the GDP response to an oil supply shock are in line with those of Blanchard and Gali (2007), who, using a structural VAR model, find no statistically significant effect since 1984 in a number of European countries (France, Italy and Germany). Also, Cunado and de Gracia (2003) find that an 
Finland

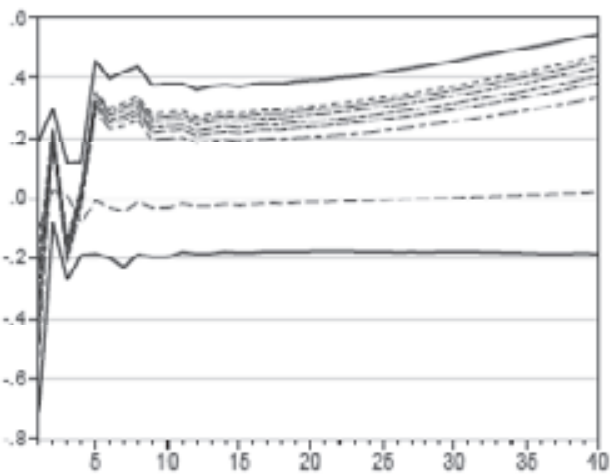

Suoden

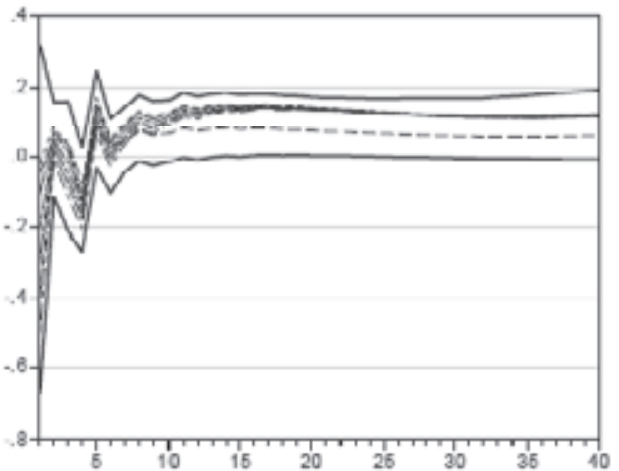

Figure 6. The impulse responses of domestic GDP to a positive oil supply shock using Monte Carlo integration and alternative impact response restrictions

Note: The dotted lines represent responses with different impact response restrictions of the domestic GDP, and the solid lines represent minimum and maximum of these responses.

asymmetric oil price measure affects real variables in most European countries, but in Finland, the causation is relatively weak. ${ }^{22}$

Several reasons have been suggested in the literature for the lack of a clear negative effect of oil supply disruptions. Blanchard and Gali (2007) find that, in particular, this phenomenon is due to three factors. First, the increased real wage flexibility in most industrialised economies in recent years will have mitigated the real effects of oil supply shocks. ${ }^{23}$ Second, increased credibility of monetary policy has helped make the effects of shocks smaller on both inflation

${ }^{22}$ One factor that may counteract the negative effects of higher oil prices in Finland is the importance of Russia as an export destination for Finnish goods; they accounted for about $10 \%$ of the value Finland's total exports in the year 2006. Being one of the most important oil-exporting economies in the world, Russia has benefited from the recent rise in the oil price and this presumably may have had spillover effects. For Sweden, however, Russia is not an important export destination (about $2 \%$ of total exports in 2006). Another, less important, factor might be the existence of oil refining industry in both countries. This effect is likely to be very small, since the proportion of the sector of total exports (less than $4 \%$ in both countries) and of value added (about $0.5 \%$ in Finland and about $0.2 \%$ in Sweden) is small. Furthermore, it is obvious that the parameter of interest in oil refining is the refining margin between the price of the end product and the price of crude oil, and not just the price of crude oil.

${ }^{23}$ This claim has been refuted by some authors in the case of the US, but they do seem more relevant for European countries with traditionally more rigid labour markets. and output and third, the importance of oil for more service-based economies has declined in recent years. Furthermore, according to some recent studies (see, for example, Barsky and Kilian (2004) and Kilian (2009)), oil demand shocks tend to have a larger effect on real variables than supply shocks. Hence, oil shocks aren't without consequences even though the effects of supply shocks may be minor or difficult to identify.

Of course, the way the experiment of Figure 6 is set out implies that the effect in Finland and Sweden is ambiguous even though the impulse response of the world GDP, measured by the OECD industrial production, is in fact negative at certain horizons. This could at least in part be due to the problems of measuring the global real economic activity by using industrial production as its proxy, but still, it makes the response of the domestic GDP variables all the more puzzling. Nevertheless, these results give support to the ambiguous effects of oil shocks on real economic activity found in several studies during recent years. Clearly, however, understanding the effects of oil supply shocks on real economic activity is an open issue requiring further research.

\section{Conclusions}

This paper presents a unique way of identifying the effects of oil supply shocks in a small open 
economy. More specifically, I define oil supply shocks as events and measure their effects on crude oil futures' prices in financial markets at different maturities. The relative size of these shocks is then forced to equal the relative size of an orthogonal oil shock in a simple 5-variable restricted VAR system for a small open economy at different horizons. This allows for constructing an identification scheme that reveals the impulse responses of the variables in the model. Thus, this paper presents an alternative approach to the conventional recursive Choleski type decomposition approach to identifying the effects of a shock on macroeconomic variables.

The paper shows how to apply this methodology to a small open economy. A restricted VAR system is applied, since some of the variables in the model do not have a contemporaneous effect on all the other variables. Specifically, domestic variables (in this case, inflation and GDP) of a small open economy do not have an effect on variables like global crude oil price or global GDP. The efficient estimation method (FGLS) is also different from a normal VAR system (OLS).

Due to the way the model is identified, point estimates cannot be used for analysis. This is confirmed by a rank test for the identification matrix, which finds this matrix to be of deficient rank. This leads to a partial identification bootstrapping procedure being used for inference, and I have to resort to confidence intervals as the point estimates of the impulse responses cannot be computed. For comparison, I also report results using more traditional Monte Carlo integration techniques.

The proposed methodology is applied to two illustrative example cases, Finland and Sweden. Even though the confidence intervals in the bootstrapping procedure are large, some conclusions can be drawn. Results imply that the effect of an oil supply shock that raises the price of crude oil is positive on inflation, even though not statistically so in the benchmark case for Finland. However, the effect for domestic GDP is ambiguous for both countries, although the impact response for Finland is puzzlingly large. This supports the view that finding a long-lasting negative effect of recent oil price hikes on GDP in industrialised oil-importing economies in recent years is very difficult. 


\section{Appendix A. Partial identification ${ }^{24}$}

Here I describe how to construct the confidence interval $A$ for the vector $\alpha$ when $A^{+}$denotes the parameter space for $\alpha$, the restrictions $R \alpha=r$ must be satisfied, $R$ is estimated by $\hat{R}, r$ is estimated by $\hat{r}, R$ may be rank deficient, $T^{1 / 2}(\operatorname{vec}(\hat{R})-\operatorname{vec}(R)) \rightarrow_{d} N\left(0, V_{R}\right)$ and $T^{1 / 2}(\hat{r}-r) \rightarrow{ }_{d} N\left(0, V_{R}\right) \cdot{ }^{25}$ Consider the GMM objective function

$$
S(\alpha)=T(\hat{R} \alpha-\hat{r})^{\prime}\left[\left(\alpha^{\prime} \otimes I_{K}\right) \widehat{V}_{R}\left(\alpha \otimes I_{K}\right)+\widehat{V}_{r}\right]^{-1}(R \alpha-r) .
$$

In standard GMM terminology, this is the continuous updating GMM objective function. The estimator $\hat{\alpha}$ that minimises this objective function is not consistent for the true $\alpha$ because of the rank deficiency of the matrix $R$. However, $S\left(\alpha_{0}\right)$ has $\chi^{2}$ distribution regardless of the rank of $R$ where $\alpha_{0}=\arg \min _{\alpha} S(\alpha)$. Accordingly, the confidence interval

$A=\left\{\alpha \in A^{+}: S(\alpha) \leq F_{\chi^{2}}\right\}$

is a confidence interval for $\alpha$ with asymptotic coverage $85 \%$, regardless of the rank of $R$, where $F_{\chi^{2}}$ denotes 85th percentile of a $\chi^{2}$ distribution (with degrees of freedom equal to the number of elements in $r$ ). This confidence interval is therefore immune to the rank deficiency of $R$.

The use of such confidence intervals in models that are not fully identified was proposed by Stock and Wright (2000), where they are referred to as S-sets. If the matrix $R$ is rank deficient, then there exists a subspace of vectors $\alpha$ that are observationally equivalent to $\alpha_{0}$. Any vector in this subspace must be included in $A$ with probability 1 . Any other vector $\alpha$ will be excluded from $A$.

Concretely, I proceed by forming a grid of about 6.7 million points in $A^{+}$. For each point in this grid, I calculate the objective function in (A1). If this is above the critical value, I ignore the point and move on to the next point in the grid. On the other hand, if $S(\alpha)$ is below the critical value, I include that value of $\alpha$ in the confidence interval $A$. For each such accepted $\alpha$, I compute the lower and upper bounds of the bootstrap confidence intervals for all the parameters of interest (which are the impulse responses of the variables at different horizons), conditional on that $\alpha$. Each bootstrap replication includes calculating a new $\theta$ from the bootstrap sample while holding $\alpha$ fixed. I then construct the confidence intervals from 500 replications using the Runkle (1987) bootstrap method. Having cycled through all the points in the grid, my confidence intervals for the impulse responses are given by the smallest and largest values of these percentiles. ${ }^{26}$

\section{Appendix B. Testing the rank of the $R$ matrix}

Several tests have been suggested in the literature to test for the rank of a stochastic matrix (for example, Cragg and Donald (1997) and Kleibergen and Paap (2006)). However, few of these are suited to testing a matrix whose covariance matrix is not full rank, which is the case with the R matrix. A test that is robust to this specification is introduced by Robin and Smith (2000) and used in this paper. ${ }^{27}$ In particular, the test allows for the covariance matrix to be of deficient, or even unknown rank.

\footnotetext{
24 This section draws heavily on Faust et al. (2004).

${ }_{25}$ Since T represents a count of months and $\hat{r}$ is based on a selected subset of days, the method might have, in principle, resulted in a sample size for $\hat{r}$ that is very different from $T$. In this case, the two samples turn out to be of roughly similar size. I thank an anonymous referee for pointing this out.

${ }^{26}$ I have used RATS to carry out the procedure, and the code is available upon request.

${ }^{27}$ I thank Pentti Saikkonen for suggesting this test statistic. For more details on the properties and assumptions of the test statistic, see Robin and Smith (2000).
} 
Robin and Smith (2000) introduce a test for the null hypothesis that the rank of matrix $R$ is $r^{*}$; $H_{0}: r k(R)=r^{*}$, versus the alternative hypothesis $H_{1}: r k(R)>r^{*}$. The Wald form of the relevant statistic is

$$
\operatorname{CRT}_{r *}^{W}=T \sum_{i=r *+1}^{q} L_{i}
$$

where $T$ is the number of observations, $r^{*}$ is the rank that is tested, $q$ is the number of columns in the matrix (in this case 5), and $L_{i}$ are the ordered estimators of the characteristic roots derived from $\widehat{\Sigma} \hat{R} \widehat{\Psi} \hat{R}^{\prime}, \hat{L}_{1} \geq \ldots \geq \hat{L}_{q}$, which solve the equation

$$
\left|\widehat{R} \widehat{\Psi} \hat{R}^{\prime}-L \widehat{\Sigma}^{-1}\right|=0 .
$$

In this case, the test is performed without loss of generality so that both $\Sigma$ and $\Psi$ are $I_{q}$ matrices. The test is performed sequentially starting at rank zero, and if the null hypothesis is rejected, the rank to be tested is increased by one until the null is accepted.

The limiting distribution of $C R T$, when $r^{*}<q$, is described by

$$
\sum_{i=1}^{t *} L_{i}^{r *} Z_{i}^{2}
$$

where $t^{*} \leq \min \left\{s,\left(p-r^{*}\right)\left(q-r^{*}\right)\right\}$, where $\mathrm{s}$ is the rank of the covariance matrix of $\mathrm{R}, \Omega$, and $L_{1}^{r *} \geq \ldots \geq L_{t *}^{r *}$ are the nonzero ordered characteristic roots of the matrix

$$
\left(D_{q-r *} \otimes C_{p-r *}\right)^{\prime} \Omega\left(D_{q-r *} \otimes C_{p-r *}\right) .
$$

$\left\{Z_{i}\right\}_{i=1}^{t *}$ in equation (B3) are random independent standard normal variates and the $D_{q-r *}$ and $C_{p-r *}$ matrices are the last $q-r^{*}$ and $p-r^{*}$ columns, respectively, of matrices $D$ and $C$ that collect as columns the characteristic vectors associated with $\tau^{2}$ of

$$
\left|R \Psi R^{\prime}-\tau^{2} \Sigma^{-1}\right|=0
$$

for $C$ and

$$
\left|R^{\prime} \Sigma R-\tau^{2} \Psi^{-1}\right|=0
$$

for $D$.

Results of the test for both Finland and Sweden in the benchmark are reported in the table below. Rank deficiency is very clear cut for both cases, as the rank implied for $R$ is 2 . Thus full identification of the model is not possible and partial identification must be carried out.

Table A1. Robin-Smith rank test

\begin{tabular}{lcccc}
\hline & & Finland & & Sweden \\
Rank & Test value & p-value & Test value & p-value \\
\hline 0 & 302.2 & 0.00 & 270.7 & 0.00 \\
1 & 64.6 & 0.00 & 60.6 & 0.00 \\
2 & 3.4 & 0.95 & 3.4 & 0.95 \\
3 & 1.4 & 0.85 & 2.1 & 0.56 \\
4 & 0.2 & 0.69 & 0.7 & 0.40 \\
\hline
\end{tabular}




\section{Appendix C. Monte Carlo integration using pure-sign restriction approach}

The strategy used in the Monte Carlo integration is based on that of Uhlig (2005) with a pure-sign restriction approach.

Let $b$ and $\mathrm{S}$ be the OLS estimates of full VAR coefficient vector $\beta$ and covariance matrix of residuals $\Sigma$, respectively. It can then be shown that $\Sigma$ is Normal-inverse Wishart with

$$
\Sigma^{-1} \sim W i s h a r t\left[(T S)^{-1}, T-P\right]
$$

where $T$ is the number of observations and $P$ is the number of explanatory variables, and that

$$
\beta \sim N\left[b, \Sigma \otimes\left(X^{\prime} X\right)^{-1}\right]
$$

where $X$ is the matrix of dependent variables.

In each draw, the covariance matrix from the full VAR model is drawn from the inverse Wishart distribution, and this is then used in the restricted VAR model to calculate the difference between the FGLS point estimates and the draw. To achieve this, it helps to simplify the covariance matrix in $(\mathrm{C} 2)$ to:

$$
\left(F_{\Sigma} \otimes F_{X X}\right)\left(F_{\Sigma} \otimes F_{X X}\right)^{\prime}=F_{X X} V F_{\Sigma}^{\prime}
$$

where $F_{\Sigma} F_{\Sigma}^{\prime}=\Sigma$ and $F_{X X} F_{X X}^{\prime}=\left(X^{\prime} X\right)^{-1} V$ is a $P \times K \mathrm{~V}$ matrix of Normal draws. For the decomposition of $F_{X X}$ and $F_{\Sigma}$, Choleski decomposition is used. ${ }^{28}$ Equation (C3) thus produces a random $P \times K$ matrix, which is then added to the matrix of the point estimates to complete the coefficients for the draw.

The identification scheme is then carried out as detailed above, for each draw. Certain restrictions are then set on the impact responses, and draws that fulfill these restrictions are stored, whilst others are discarded. The impulse responses and their confidence intervals are then calculated based on the accepted draws.

\footnotetext{
28 The results are robust to any kind of decomposition.
} 


\section{Appendix D. Results with Monte Carlo integration}
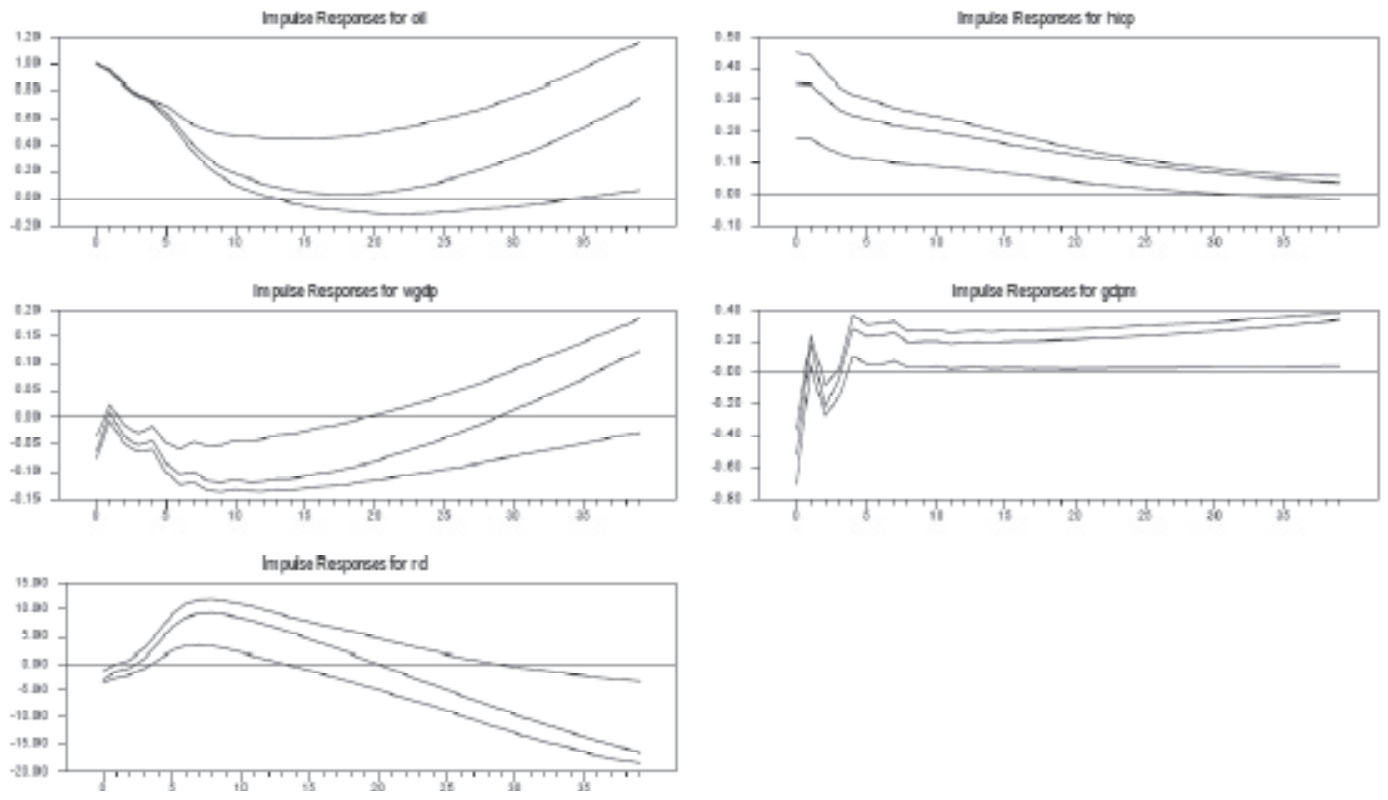

Figure 7. Impulse responses for Finland using Monte Carlo integration and sign restrictions
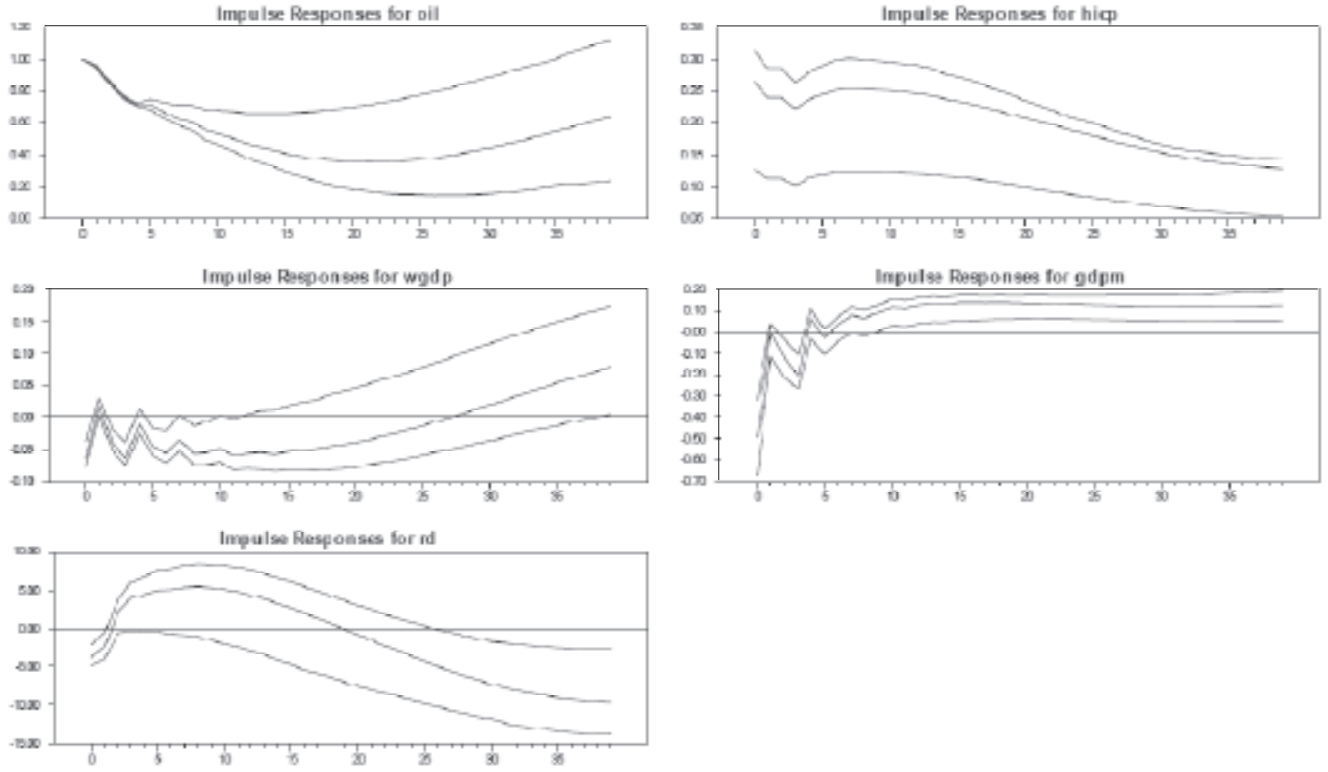

Figure 8. Impulse responses for Sweden using Monte Carlo integration and sign restrictions 
Finnish Economic Papers 1/2011 - Marko Melolinna
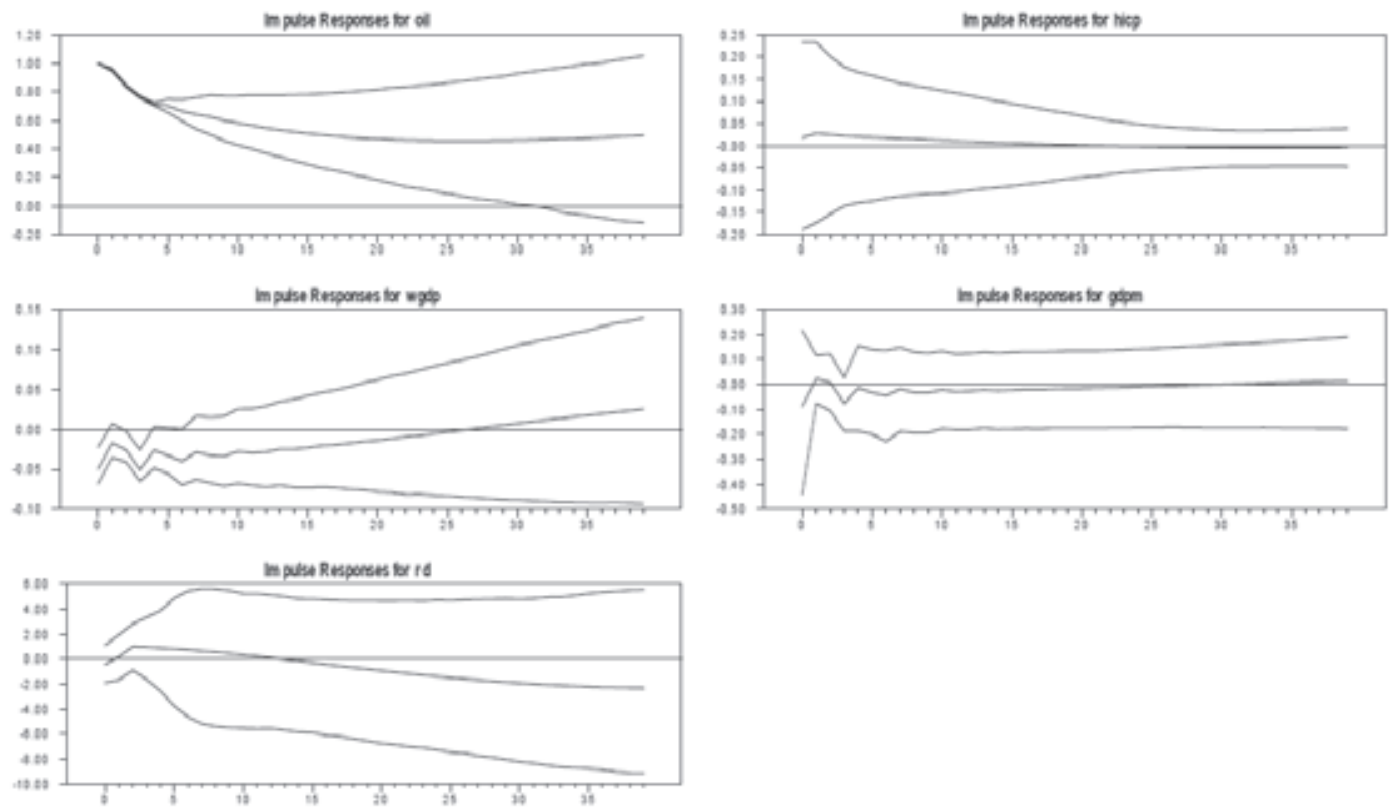

Figure 9. Impulse responses for Finland using Monte Carlo integration
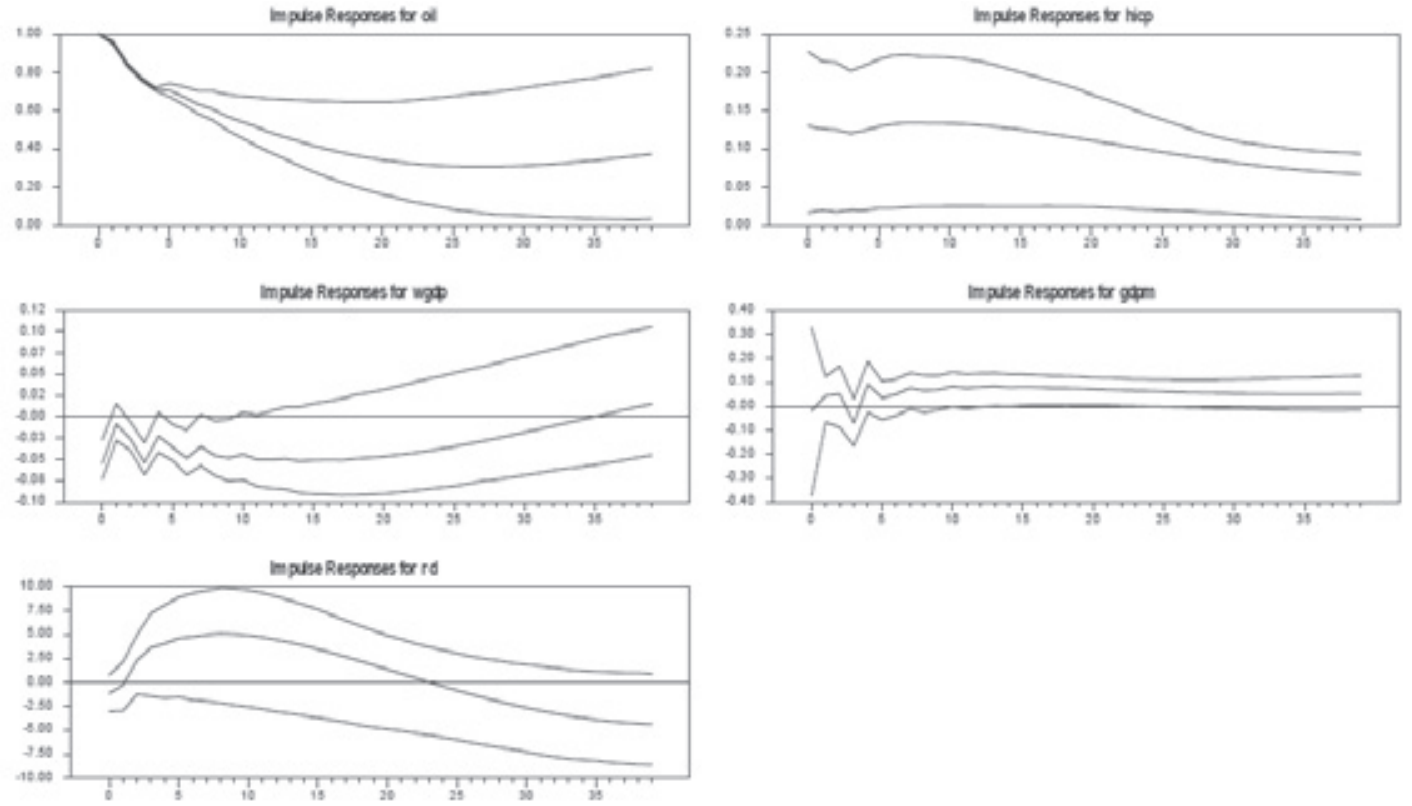

Figure 10. Impulse responses for Sweden using Monte Carlo integration 


\section{References}

Anzuini, A., M.J. Lombardi, and P. Pagano (2010). The impact of monetary policy shocks on commodity prices. ECB Working Paper No. 1232.

Anzuini, A., P. Pagano, and M. Pisani (2007). Oil supply news in a VAR: Information from .financial markets. Banca D.Italia Temi di discussion del Servizio Studi, Number 632 - June 2007.

Barsky, R., and L. Kilian (2004). Oil and the macroeconomy since the 1970s.National Bureau of Economic Research Working Paper No. 10855, October.

Blanchard, O.J., and J. Gali (2007). The macroeconomic effects of oil shocks: Why are the 2000s so different from the 1970s? National Bureau of Economic Research, Working Paper 13368.

Burbridge, J., and A. Harrison (1984). "Testing for the effects of oil-price rises using vector autoregressions." International Economic Review 25, 459-484.

Cavallo, M., and T. Wu (2006). Measuring oil-price shocks using market-based information. Federal Reserve Bank of Dallas Working Paper No. 28.

Cragg, J.G., and S.G. Donald (1997). "Inferring the rank of a matrix." Journal of Econometrics 76, 223-250.

Cunado, J., and F.P. de Gracia (2003). "Do oil price shocks matter? Evidence for some European countries." Energy Economics 25, 137-154.

Faust, J., E.T. Swanson, and J.H. Wright (2004). "Identifying VARS based on high frequency futures data." Journal of Monetary Economics 51, 1107-1131.

Frankel, J.A. (2006). The effect of monetary policy on real commodity prices. National Bureau of Economic Research Working Paper 12713, December.
Hamilton, J.D. (1983). "Oil and the macroeconomy since world war II.” The Journal of Political Economy 91, 228-248.

Hooker, M.A. (1996). "What happened to the oil pricemacroeconomy relationship?" Journal of Monetary Economics 38, 195-213.

Jimenez-Rodriguez, R., and M. Sanchez (2005). "Oil price shocks and real GDP growth: Empirical evidence for some OECD countries." Applied Economics 37, 201228.

Kilian, L. (2006). Exogenous oil supply shocks: How big are they and how much do they matter for the U.S. economy? Mimeo, University of Michigan, October 9.

Kilian, L. (2009). "Not all oil price shocks are alike: Disentangling demand and supply shocks in the crude oil market." American Economic Review 99, 1053-1069.

Kleibergen, F., and R. Paap (2006). "Generalized reduced rank tests using the singular value decomposition." Journal of Econometrics 133, 97-126.

Lutkepohl, H. (2005). New Introduction to Multiple Time Series Analysis: Springer-Verlag.

Robin, J.-M., and R.J. Smith (2000). "Tests of rank." Econometric Theory 16, 151-175.

Runkle, D.E. (1987). "Vector autoregressions and reality." Journal of Business and Economic Statistics 5, 437-442.

Sims, C., J.H. Stock, and M.W. Watson (1990). "Inference in linear time series models with some unit roots." Econometrica 58, 113-144.

Stock, J., and J. Wright (2000). "GMM with weak identification." Econometrica 68, 1055-1096.

Uhlig, H. (2005). "What are the effects of monetary policy on output? Results from an agnostic identification procedure." Journal of Monetary Economics 52, 381-419. 